\title{
The Effect of Accelerated Ageing on Reaction-to-Fire Properties-Composite Materials
}

\author{
Anna Sandinge (D)*, RISE Research Institutes of Sweden, PO Box 857, 50115 \\ Borås, Sweden and DTU Technical University of Denmark, Kongens \\ Lyngby, Denmark \\ Per Blomqvist, RISE Research Institutes of Sweden, PO Box 857, 50115 \\ Borås, Sweden \\ Lars Schiøtt Sørensen, DTU Technical University of Denmark, Kongens \\ Lyngby, Denmark \\ Anne Dederichs, RISE Research Institutes of Sweden, PO Box 857, 50115 \\ Borais, Sweden and DTU Technical University of Denmark, Kongens \\ Lyngby, Denmark
}

Received: 15 January 2021/Accepted: 30 October 2021/Published online: 26 November 2021

\begin{abstract}
As material age, the durability, strength, and other mechanical properties are impacted. The lifespan of a material generally decreases when exposed to weathering conditions such as wind, temperature, humidity, and light. It is important to have knowledge of how materials age and how the material properties are affected. Regarding materials' fire behaviour and the effect of ageing on these properties, the knowledge is limited. The research questions of the current work are: Are the fire properties of composite materials affected by ageing? And if so, how is it affected? The study is on material at Technology Readiness Level 9 (TRL). In this study, three composite fibre laminates developed for marine applications were exposed to accelerated ageing. Two different ageing conditions were selected, thermal ageing with an increased temperature of $90^{\circ} \mathrm{C}$ and moisture ageing in a moderately increased temperature of $40^{\circ} \mathrm{C}$ and a relative humidity of $90 \%$. Samples were collected after one, two and four weeks of ageing. The reaction-to-fire properties after ageing was evaluated using the ISO 5660-1 cone calorimeter and the EN ISO 5659-2 smoke chamber with FTIR gas analysis. The test results showed that the fire behaviour was affected. Two of the composite laminates, both phenolic/basalt composites, showed a deteriorated fire behaviour from the thermal ageing and the third composite laminate, a PFA/glass fibre composite, showed an improved fire behaviour both for thermal and moisture ageing. The smoke toxicity was affected by the accelerated ageing, especially for the PFA/glass fibre composite that showed a higher production of $\mathrm{CO}$ and $\mathrm{HCN}$, both for the thermal aged and the moisture aged samples.
\end{abstract}

Keywords: Accelerated ageing, Thermal exposure, Moisture exposure, Reaction-to-fire, Cone calorimeter, Smoke density, Toxicity, Composite laminates

\footnotetext{
*Correspondence should be addressed to: Anna Sandinge, E-mail: anna.sandinge@ri.se
} 


\section{Introduction}

New products and materials are put on the market every day. These products are considered to have passed their final phase of development and are hence at TRL (Technology Readiness Level) 9. Regarding fire properties, tests for classification are made with newly produced samples. At the same time, it is known that material properties change with time, especially when exposed to temperature, humidity, wind and light. It has been shown in many studies that mechanical properties change with time resulting in a weakening in these properties [1-19]. A comparable extended knowledge is not currently available regarding the effect of ageing on reaction-to-fire performance. Some of the currently available studies have been presented in review papers by Vahabi et al. [5] and Sandinge et al. [20]. Both present a limited number of studies, showing that accelerated ageing influences the fire performance or has a chemical degrading effect on the flame retardants used in the studied material. However, in literature, there is a lack of knowledge regarding the effect of accelerated ageing on the fire performance, especially for composite materials. The question rises, whether the overall fire safety properties of the products are unaffected by ageing and no further knowledge on the material is needed, or not.

A useful tool to help evaluating the properties of materials at a later stage of their lifetime, is to expose the material to accelerated ageing conditions. Degradation and damage in materials can then occur after a few days or weeks only, that normally would occur after several years in end-use climate. When selecting the ageing method, it is important to choose an exposure that is not too tough, in order not to damage the material in a way that would not occur during real-time ageing. The degradation can be both chemical and physical. If the selection of ageing method is incorrect, there is a possibility that chemical reactions or physical degradation can occur which would not take place when aged in real-time with end-use climate $[5-8,21]$.

Thermal ageing, i.e., exposure to an increased temperature, is the most widely used accelerated ageing method. The polymer chains in the material are broken by thermally activated mechanisms, resulting in a change of the material properties. The degradation rate is temperature dependent and increases with increasing temperature $[5,11]$. The Arrhenius Rate Law can be used as a tool to correlate time scales with thermal ageing, since the chemical reaction rate increases exponentially with temperature. The rate law can be simplified to a rule-of-thumb saying that the reaction rate doubles for every $10 \mathrm{~K}$ increase in temperature [9, 21-24].

Moisture ageing can be conducted in several ways, it could include the exposure to an atmosphere with an increased relative humidity or alternatively immersion in a liquid. Moisture exposure is a tough environment for many materials resulting in material structure damage. The moisture can be absorbed and then cause dimensional changes such as swelling and deterioration of the material properties $[7,10]$.

The effect of accelerated ageing on the reaction-to-fire properties of a phenolic/ basalt composite developed for applications in ships has earlier been reported on 
in a paper by Sandinge et al. [24]. The composite was aged using two different methods: 1) thermal exposure of $90^{\circ} \mathrm{C}$ and 2) moisture exposure with an atmosphere of $40{ }^{\circ} \mathrm{C}$ and $90 \%$ relative humidity. Samples were exposed to ageing climates for 1 week, 2 weeks and 4 weeks. The evaluation of reaction-to-fire properties reported on was made using the cone calorimeter, ISO 5660-1 [25]. The results showed that the composite was clearly affected by the accelerated ageing. The time to ignition was decreased, and both the heat release and the smoke production were increased. The accelerated ageing atmosphere with increased temperature (thermal ageing) gave in this case the largest effects on the fire behaviour.

In another study by Le Lay et al. [12] a phenolic/glass laminate was aged using immersion in $60^{\circ} \mathrm{C}$ salt water during $1000 \mathrm{~h}$. The fire performance was evaluated using the cone calorimeter. The aged sample exploded during the fire tests due to water uptake in microvoids in the material. During the heat exposure, trapped water rapidly vaporized and lead to the explosion, clearly showing that the material is sensitive to moisture exposure.

The aim of this paper is to further evaluate the accelerated ageing effect on the reaction-to-fire properties of two additional composite materials developed for applications in ships. Ageing of construction materials would be of especial concern for applications in harsh marine applications. The selected composite materials were exposed to thermal ageing and moisture ageing, just as with the phenolic/ basalt composite reported on earlier [24]. The effect from the accelerated ageing on the reaction-to-fire properties were evaluated using the ISO 5660-1 cone calorimeter and additionally the EN ISO 5659-2 smoke chamber according to IMO FTP Code 2010, Part 2 with the additional FTIR gas analysis. Results from smoke chamber tests are here included for the afore mentioned phenolic/basalt composite.

\section{Method}

The methods applied in the study are described in the current chapter. At first the material used for the study is presented, followed by the analysis of the materials using Thermal Gravimetric Analysis (TGA). The TGA was used to identify the temperatures for thermal stability of the composites. This is followed by a description of the accelerated ageing methods applied to prepare the material for the fire study. Then the methods used for the fire tests are presented; the cone calorimeter and the smoke chamber test with FTIR gas analysis, delivering the density and the toxic gas content of the smoke.

\subsection{Material}

In total three fibre reinforced polymer (FRP) composite materials were selected for the study of ageing effects on the reaction-to-fire properties. These were all materials developed to be used as construction materials in ships within the EU project RAMSSES [26]. The first composite laminate (FRP 1) consisted of a phenolic resin and basalt fibres with a density of $1000 \mathrm{~kg} / \mathrm{m}^{3}$ and a thickness of $3 \mathrm{~mm}$ [24]. The second composite laminate (FRP 2) contained the same phenolic resin 
and basalt fibres as FRP 1. The density of FRP 2 was in this case $300 \mathrm{~kg} / \mathrm{m}^{3}$ and the thickness was $15 \mathrm{~mm}$. The composite laminates FRP 1 and FRP 2 contained an expansion agent, active during the composite manufacturing process, resulting in a change in density of the final composite. The expansion agent is expected to be fully consumed during the manufacturing process of the composite and should therefore as such, not have any influence on the reaction-to-fire properties. FRP 1 and FRP 2 was manufactured using injection moulding. The third composite laminate used in this study, FRP 3, contained Poly Furfuryl Alcohol (PFA) resin reinforced with glass fibres. The density was $1700 \mathrm{~kg} / \mathrm{m}^{3}$ and the thickness was $3 \mathrm{~mm}$. The FRP 3 laminate was manufactured using a prepreg under vacuum. The fibre volume fraction was not known for any of the composite laminates due to confidentiality of the detailed production process.

\subsection{Testing with $T G A$}

The temperature used for exposure in thermal ageing should not result in any critical processes of the test material that do not occur at the service temperature, such as e.g., glass transition or pyrolysis. To investigate that the selected temperature was not too high, the thermal stability of the composites was analysed using Thermal Gravimetric Analysis (TGA) [27], with a Netzsch STA 443 F3 Jupiter instrument. The mass loss of the material was measured as the temperature increased with a temperature ramp of $10 \mathrm{~K} / \mathrm{min}$ up to $1000^{\circ} \mathrm{C}$. In addition, a temperature ramp of $2 \mathrm{~K} / \mathrm{min}$, up to $200^{\circ} \mathrm{C}$, was used to further evaluate the thermal stability at lower temperatures and with a slower temperature increase. The tests were conducted with an atmosphere of ambient air and a gas flow rate of $50 \mathrm{ml} /$ min. TGA tests were conducted with FRP 1 and FRP 3. Tests were not conducted with FRP 2 as the general behaviour was expected to be similar with FRP 1. The initial mass of the FRP 1 samples was $27 \mathrm{mg}$ to $44 \mathrm{mg}$, and for FRP 3 the initial mass was $11 \mathrm{mg}$ to $16 \mathrm{mg}$.

\subsection{Accelerated Ageing Methods}

The selected accelerated ageing methods were thermal ageing and moisture ageing. The samples exposed to thermal ageing were stored in $90^{\circ} \mathrm{C}$ for 1 week, 2 weeks and 4 weeks, using an oven from Binder. Using the rule-of-thumb of the Arrhenius Rate Law these ageing condition correlates to an end-use of up to 10 years with a surrounding temperature of $20^{\circ} \mathrm{C}$ [24]. The samples exposed to moisture ageing were stored in a climate chamber, FITOCLIMA 600PH-CI from Aralab, set to $40^{\circ} \mathrm{C}$ and $90 \%$ relative humidity for 1 week, 2 weeks and 4 weeks. All samples were stored in a conditioning climate of $23^{\circ} \mathrm{C}$ and $50 \%$ relative humidity before the accelerated ageing and after the accelerated ageing exposure until time for the fire testing. All samples were weighed before placed in the ageing climate and weighed again before fire testing, in both cases as conditioned. 


\subsection{Cone Calorimeter Testing}

Tests were conducted using a cone calorimeter from Fire Testing Technology (FTT), according to ISO 5660-1 [25]. The test sample is mounted horizontally beneath a radiation cone and exposed to a thermal radiation of $50 \mathrm{~kW} / \mathrm{m}^{2}$. Pyrolysis gases are produced when the sample is exposed to the heat flux and ignited by a spark igniter. An exhaust hood with a channel, located above the sample holder and the radiation cone collects all the gases, and analysis of $\mathrm{O}_{2}, \mathrm{CO}_{2}$ and $\mathrm{CO}$ are made in order to determine the heat release rate based on the oxygen consumption method. Important output parameters such as time to ignition, peak Heat Release Rate (peak HRR), Total Heat Release (THR) and Total Smoke Production (TSP) were recorded and expressed per unit area. Duplicate tests were run, both for the unaged samples and aged samples. The test time was 20 min.

Observations of burning from the rear side of the specimen holder has been made during earlier tests with composite materials in the cone calorimeter [28-32]. In these tests there was burning not only from the sample surface but also of pyrolysis gases originating from the sample edges. This results in non-representative burning of the surface of the composite laminates since it gives an extra contribution to heat and smoke production. This can, in many cases, be seen in the heat release rate curve as a second peak. The data output is in such cases not calculated from surface burning only, which is the intention of the test method. To avoid edge burning of the composite laminates in the present study, a modified specimen holder was used. With this specimen holder a larger sample of size $136 \times 136 \mathrm{~mm}$ was used. The exposed area was circular with a diameter of $106 \mathrm{~mm}$, giving an exposed area of $0.0088 \mathrm{~m}^{2}$, the same exposed areas as for the original holder as described in ISO 5660-1. As a result, the distance between sample edges and the exposed surface was increased, which was the aim to avoid the effects from pyrolysis of specimen edges. The modified specimen holder is detailed in a study by Sandinge et al. [33].

\subsection{Smoke Chamber Testing with FTIR gas Analysis}

The smoke density and the toxic gas content of the smoke were evaluated using the EN ISO 5659-2 smoke chamber test [34], apparatus from Fire Testing Technology (FTT), together with additional FTIR gas analysis, using a Thermo Scientific Antaris IGS Analyzer.

The sample with a size of $75 \times 75 \mathrm{~mm}$ is mounted in the specimen holder and located horizontally under the radiation cone in the test chamber. The distance between the specimen surface and the cone was set to $25 \mathrm{~mm}$. As the surface is heated by the radiation from the cone, smoke is evolved at the sample surface and the smoke is accumulated in the closed test chamber. The smoke density, i.e., the visibility through the smoke, is measured with a light source and a photocell. The heat flux of the cone was $50 \mathrm{~kW} / \mathrm{m}^{2}$ and there was no pilot flame used. This is one of the three test modes used in the IMO FTP Code 2010, Part 2. Duplicate tests were conducted for all materials with both unaged and aged samples. The test duration was $20 \mathrm{~min}$. 
The FTIR analysis was conducted according to EN 17,084 [35] with the gas sampling probe described by IMO FTP Code 2010 Part 2 [4]. Gas was sampled with the FTIR continuously during the full test time. The sampling flow rate used was $1.5 \mathrm{l} / \mathrm{min}$. The gas species content was recorded continuously, and the maximum concentration is reported here. The following gases were included in the analysis: carbon dioxide $\left(\mathrm{CO}_{2}\right)$, carbon monoxide $(\mathrm{CO})$, hydrogen cyanide $(\mathrm{HCN})$, hydrogen chloride $(\mathrm{HCl})$, hydrogen fluoride $(\mathrm{HF})$, hydrogen bromide $(\mathrm{HBr})$, nitrogen oxides ( $\mathrm{NO}$ and $\mathrm{NO}_{2}$ summarized as $\left.\mathrm{NO}_{\mathrm{X}}\right)$ and sulphur dioxide $\left(\mathrm{SO}_{2}\right)$.

\subsection{Uncertainties of Results}

There are some uncertainties of the results in the ageing study, shortly discussed in this section. Accelerated ageing can be conducted in numerous of ways. The selected ageing methods represent only two possible ways to age materials. The ageing methods with thermal exposure and moisture exposure were selected due to their relevance for the end use application of the materials.

The selected fire test methods, cone calorimeter (ISO 5660-1) and smoke density chamber (EN ISO 5659-2), both states that triplicate tests should be conducted. However, in this ageing study, duplicate tests were conducted with both fire test methods. As a result, the uncertainty of the results is higher and must be considered. General guidelines and rules for assessment of uncertainty were decided for the ageing study based on information from the test standards. For the ISO 5660-1 cone calorimeter test, the $180 \mathrm{~s}$ mean heat release of three samples should be compared. If any of the individual tests differ more than $10 \%$ from the arithmetic mean value, another set of three samples should be tested. For the EN ISO 5659-2 smoke density test, if the $\mathrm{D}_{\mathrm{s}, \max }$ for any of the samples differs more than $50 \%$ from the mean value another three samples must be tested. However, if the difference in $\mathrm{D}_{\mathrm{s} \text {, max }}$ can be related to different burning behaviour (ignition or no ignition), no re-test is needed.

Given the uncertainty of the accelerated ageing methods and the uncertainty in the fire test methods, the guidelines were set up for the ageing study. These were used for evaluation of the repeatability of the fire performance parameters. If the value where within $5 \%$ from the mean value, the repeatability was good. A value up to $10 \%$ from the mean value was acceptable. If the value differed more than $10 \%$ from the mean value, the repeatability was assigned to be poor. However, one should note that these guidelines can be overly tough for parameters with small numbers, such as, e.g., time to ignition for the cone calorimeter.

\section{Results}

The results from the tests with the accelerated aged composite laminates, FRP 1, FRP 2 and FRP 3, are presented and compared to unaged reference laminate samples in the sections below. The detailed results from cone calorimeter tests with FRP 1 can be found in [24]. 


\subsection{TGA-Thermal Gravimetric Analysis}

The thermal stability of the original unaged composite laminates FRP 1 and FRP 3 was evaluated using TGA. The results of the tests with a temperature increase of $2 \mathrm{~K} / \mathrm{min}$, presented in Fig. 1A, show that for both the FRP 1 and the FRP 3 composite laminate, mass loss was taking place at a rather moderate and constant rate below $200^{\circ} \mathrm{C}$. The mass loss for FRP 1 was more substantial compared to the very limited mass loss for FRP 3 . When conducting TGA analysis of phenol resins in an oxygen atmosphere, an oxidation might occur and result in the small mass loss observed already at lower temperatures, as described in [36]. Another possible explanation could be release of uncured resin and water [37].The limited mass loss seen for FRP 3 would be a result of the high thermal stability of the PFA resin [38]. To conduct thermal ageing at $90^{\circ} \mathrm{C}$ with these composites seems acceptable due to the slow and steady degradation rate in this temperature range, and especially for FRP 3, which showed to be very thermally stable. For FRP 1, the degradation rate is higher, but constant, and being well below the critical temperature for pyrolysis.
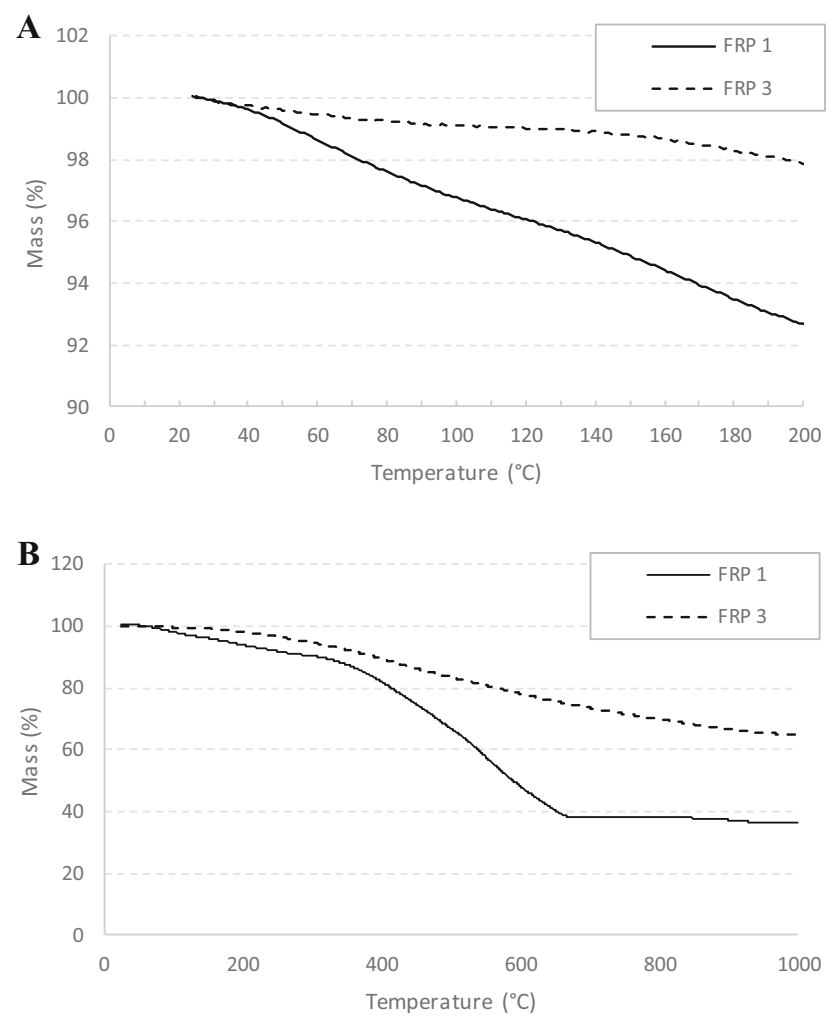

Figure 1. Test result for FRP 1 and FRP 3 composite laminates using the TGA method. (a) Temperature ramp of $2 \mathrm{~K} / \mathrm{min}$. (b) Temperature ramp of $10 \mathrm{~K} / \mathrm{min}$. 
At higher temperatures the mass loss rate increases for both composites, but they behave quite differently. Figure $1 \mathrm{~b}$ shows the TGA results from tests with a temperature increase of $10 \mathrm{~K} / \mathrm{min}$ up to $1000^{\circ} \mathrm{C}$. The mass loss of FRP 1 shows an expected behaviour, with a high mass loss rate from degradation of the phenolic resin between 400 and $600^{\circ} \mathrm{C}$ [37]. At higher temperatures the mass loss has ceased, and the results are revealing a residue content of about 40 weight- $\%$ including the basalt fibres [39, 40].

The FRP 3 laminate did not show the same behaviour. The mass was instead slowly decreasing during the full test time indicating a constant slow degradation of the PFA resin and possible some contribution from degradation of the coating of the glass fibre [41]. In both cases, the fibres would not significantly contribute to the mass loss as degradation of the fibre material is limited at temperatures below $1000^{\circ} \mathrm{C}[40]$.

The difference in degradation behaviour between FRP 1 and FRP 3 indicates that the burning behaviour in the cone calorimeter tests also will be quite different between the laminates.

\subsection{Assessment of Physical Changes of Aged Samples}

An evaluation of any physical changes of the aged samples was first made. The results from the examination of FRP 1 was presented in detail in the previous study by Sandinge et al. [24]. In summary, the thermal aged samples showed a distinct change in colour. The moisture aged samples showed some colour change, but not as distinct as the thermal aged samples. There was no shrinkage, mass change or delamination in any of the cases.

The FRP 2 samples exposed to thermal ageing showed a clear change in colour after the heat exposure. The aged samples had a darker colour. The samples did not show any significant change in mass, shrinkage, delamination or change in shape. The samples exposed to moisture ageing showed no change in colour, mass, shape or delamination. The samples are shown in Fig. 2.

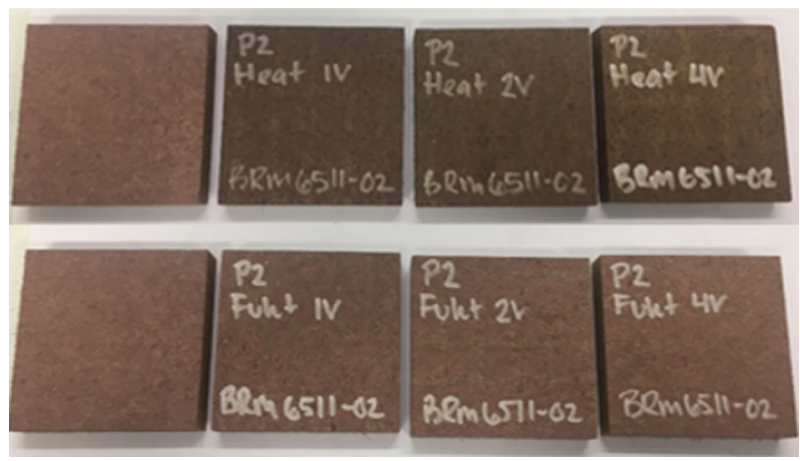

Figure 2. Samples of FRP 2 after thermal ageing (upper photo) and moisture ageing (lower photo). Sample to left unaged, then samples aged for one week, two weeks and four weeks, respectively. 


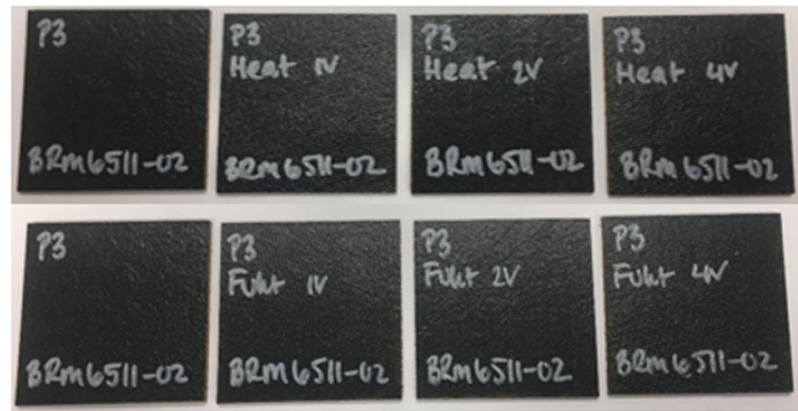

\section{Figure 3. Samples of FRP 3 after thermal ageing (Upper photo) and moisture ageing (lower photo). Sample to left unaged, then samples aged for one week, two weeks and four weeks, respectively.}

The FRP 3 composite samples did not show any significant change regarding colour, mass, shape or delamination after exposure to thermal ageing or exposure to moisture ageing. The samples are shown in Fig. 3.

\subsection{Cone Calorimeter}

The results of the cone calorimeter test are given below for the FRP 2 and FRP 3 composite laminates.

3.3.1. FRP 2 Composite The results of the tests with the FRP 2 laminate are presented in Table 1. Evaluating the results for the unaged samples first, the duplicate samples show a relatively large difference in time to ignition. However, the repeatability for both peak HRR and THR was good. The TSP for the unaged samples showed a clear difference between the duplicate tests. However, the smoke production was very low and due to the low values, the difference between the duplicates is within the tolerances of the test method.

Visual observations of the fire behaviour showed that all samples, unaged and aged, had a similar burning behaviour. There was a fast increase in fire intensity after ignition, followed by continuous burning with a gradual decrease of the heat release rate until the flames extinguished.

3.3.1.1. Samples Aged by Thermal Exposure Generally, the repeatability of the thermal aged samples was good. However, the samples aged for 1 and 2 weeks showed some variations between the duplicate tests regarding time to ignition.

In Fig. 4, the peak HRR versus time to ignition is shown. This is one simple illustrative way of displaying the heat release hazard of a material, as an early ignition in combination with a high peak in heat release rate would be an unwanted combination. The thermally aged samples all show a higher peak in heat release rate compared to the unaged, although the time to ignition was similar. The HRR was higher for the aged samples, not only in the peak value, but also during the full test. As a result, see Table 1, the THR was higher for the aged 
Table 1

Test Results of FRP 2 with the Cone Calorimeter

\begin{tabular}{|c|c|c|c|c|c|c|c|}
\hline Ageing time & $t_{\text {ign }}(s)$ & $t_{\text {ext }}(s)$ & $\begin{array}{c}\mathrm{pHRR} \\
\left(\mathrm{kW} / \mathrm{m}^{2}\right)\end{array}$ & $\begin{array}{r}\mathrm{THR}_{300} \\
\left(\mathrm{MJ} / \mathrm{m}^{2}\right)\end{array}$ & $\begin{array}{c}\text { THR } \\
\left(\mathrm{MJ} / \mathrm{m}^{2}\right)\end{array}$ & $\begin{array}{l}\mathrm{TSP}_{300} \\
\left(\mathrm{~m}^{2} / \mathrm{m}^{2}\right)\end{array}$ & $\begin{array}{c}\text { TSP } \\
\left(\mathrm{m}^{2} / \mathrm{m}^{2}\right)\end{array}$ \\
\hline \multirow[t]{2}{*}{ Unaged } & 34 & 201 & 72 & 9.2 & 25 & 22 & 36 \\
\hline & 42 & 268 & 73 & 9.2 & 25 & 13 & 16 \\
\hline$m v$ & 38 & 235 & 73 & 9.2 & 25 & 17 & 26 \\
\hline rel md \% & 11 & 14 & 0.7 & 0.0 & 0.0 & 25 & 38 \\
\hline \multicolumn{8}{|l|}{ Thermal aged } \\
\hline \multirow[t]{2}{*}{1 week } & 35 & 255 & 84 & 11 & 30 & 31 & 40 \\
\hline & 27 & 405 & 77 & 12 & 30 & 27 & 46 \\
\hline$m v$ & 31 & 330 & 81 & 12 & 30 & 29 & 43 \\
\hline rel md \% & 13 & 23 & 4.3 & 2.5 & 0.0 & 7.4 & 7.0 \\
\hline \multirow[t]{2}{*}{2 weeks } & 44 & 255 & 84 & 10 & 29 & 29 & 32 \\
\hline & 36 & 337 & 82 & 11 & 30 & 27 & 46 \\
\hline$m v$ & 40 & 296 & 83 & 11 & 30 & 28 & 39 \\
\hline rel md \% & 10 & 14 & 1.2 & 3.8 & 1.7 & 2.5 & 18 \\
\hline \multirow[t]{2}{*}{4 weeks } & 36 & 803 & 82 & 12 & 36 & 29 & 32 \\
\hline & 37 & 851 & 82 & 12 & 35 & 28 & 37 \\
\hline$m v$ & 37 & 827 & 82 & 12 & 36 & 29 & 35 \\
\hline rel md \% & 1.4 & 2.9 & 0.0 & 0.0 & 1.4 & 1.7 & 7.2 \\
\hline \multicolumn{8}{|l|}{ Moisture aged } \\
\hline \multirow[t]{2}{*}{1 week } & 51 & 232 & 72 & 9.1 & 28 & 14 & 16 \\
\hline & 41 & 296 & 70 & 9.6 & 28 & 12 & 15 \\
\hline$m v$ & 46 & 264 & 71 & 9.3 & 28 & 13 & 16 \\
\hline rel md \% & 11 & 12 & 1.4 & 2.4 & 0.0 & 5.6 & 3.2 \\
\hline \multirow[t]{2}{*}{2 weeks } & 34 & 273 & 74 & 10 & 29 & 15 & 24 \\
\hline & 44 & 228 & 77 & 8.5 & 25 & 19 & 33 \\
\hline$m v$ & 39 & 251 & 76 & 9.3 & 27 & 17 & 29 \\
\hline rel md \% & 13 & 9.0 & 2.0 & 8.1 & 7.4 & 12 & 16 \\
\hline \multirow[t]{2}{*}{4 weeks } & 72 & 175 & 68 & 7.0 & 22 & 9.3 & 21 \\
\hline & 76 & 207 & 66 & 7.2 & 26 & 8.8 & 9.0 \\
\hline$m v$ & 74 & 191 & 67 & 7.1 & 24 & 9.1 & 15 \\
\hline rel md \% & 2.7 & 8.4 & 1.5 & 1.4 & 8.3 & 2.8 & 40 \\
\hline
\end{tabular}

$\mathrm{t}_{\mathrm{ign}}$-time to ignition

$t_{\text {ext }}$-time to extinguishment

$m v$ is the mean value of the duplicate tests and rel $m d \%$ is the relative mean deviation in percentage from the mean value

samples. The 4-weeks aged samples showed the highest increase in THR. Further, the total smoke production generally was somewhat higher for the aged samples, but still relatively low, as can be seen in Table $1 . z$

3.3.1.2. Samples Aged by Moisture Exposure The repeatability of the FRP 2 duplicate tests for the moisture aged samples was generally good, but showed some variation especially in time to ignition and TSP. The duplicate samples aged for 1 week, and 2 weeks as well, showed a clear difference in time to ignition, but the repeatability of the four weeks aged samples was good. The repeatability of peak HRR and THR were in all cases good. The TSP for the 1-week aged sam- 


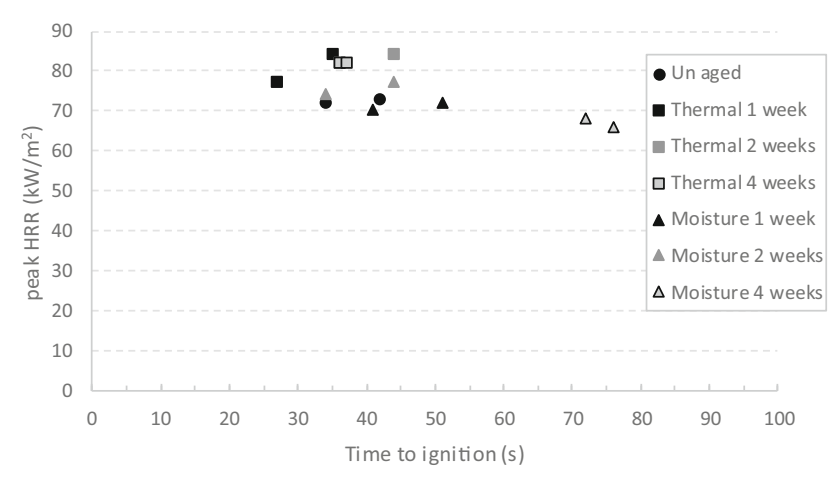

\section{Figure 4. Peak heat release rate versus time to ignition for the cone calorimeter tests with FRP 2.}

ples was similar to each other, but for the 2- and 4-weeks aged samples there was in some cases a larger variation between the duplicate samples. Noticeable is that the smoke values were in all cases very low, and regarding the smoke produced, the results can still be seen as acceptable.

When comparing the aged samples with the unaged, the effect of moisture exposure after 1 and 2 weeks was small, regarding all parameters, as shown in Table 1 and Fig. 4. The result for the samples aged for 4 weeks showed, however, a large change. The time to ignition was much longer and the peak HRR as well as the $\mathrm{THR}_{300}$ was lower. Also, the smoke production was generally lower for the 4 weeks aged samples.

3.3.2. FRP 3 Composite The repeatability of the duplicate tests with the unaged FRP 3 laminate was generally good, as demonstrated in the time to ignition, burning time and peak HRR. There was some larger, but acceptable, differences in the THR and TSP results, as shown in Table 2.

Visual observations of the burning behaviour of the FRP 3 samples showed that after a few seconds of burning, the flames self-extinguished. As stated by the standard, ISO 5660-1 [25], the spark igniter was again inserted over the specimen surface. The samples re-ignited and continued to burn, and the spark igniter was then removed from the specimen. All samples, unaged and aged showed this burning behaviour, with exception for one of the samples thermally aged for 4 weeks. This sample did not extinguish early in test, it continued to burn.

Another observation made regarding the burning behaviour was that many of the tests showed smoke occurring from the rear side of the specimen holder. Sandinge et al. [33] have earlier showed that this is a common burning behaviour for the FRP 3 composite laminate. The production of pyrolysis gases within the fibre layers of the composite is fast. And, as a result, the pyrolysis gases seep out at the rear side of the sample holder, shown by the smoke. However, no ignition was observed of the smoke at the rear side of the specimen holder in the tests reported on in the present study. 
Table 2

Test Results of FRP 3 with the Cone Calorimeter

\begin{tabular}{|c|c|c|c|c|c|c|c|}
\hline $\begin{array}{l}\text { Ageing } \\
\text { time }\end{array}$ & $\begin{array}{l}\mathrm{t}_{\mathrm{ign}} \\
(\mathrm{s})\end{array}$ & $\begin{array}{l}t_{\text {ext }} \\
(s)\end{array}$ & $\begin{array}{c}\mathrm{pHRR}(\mathrm{kW} / \\
\left.\mathrm{m}^{2}\right)\end{array}$ & $\begin{array}{c}\mathrm{THR}_{300}(\mathrm{MJ} / \\
\left.\mathrm{m}^{2}\right)\end{array}$ & $\begin{array}{c}\text { THR }(\mathrm{MJ} / \\
\left.\mathrm{m}^{2}\right)\end{array}$ & $\begin{array}{c}\mathrm{TSP}_{300}\left(\mathrm{~m}^{2} /\right. \\
\left.\mathrm{m}^{2}\right)\end{array}$ & $\begin{array}{c}\operatorname{TSP}\left(\mathrm{m}^{2}\right. \\
\left.\mathrm{m}^{2}\right)\end{array}$ \\
\hline \multirow[t]{2}{*}{ Unaged } & 33 & 489 & 214 & 11 & 32 & 30 & 30 \\
\hline & 30 & 496 & 228 & 14 & 42 & 26 & 26 \\
\hline$m v$ & 32 & 493 & 221 & 13 & 37 & 28 & 28 \\
\hline rel md \% & 4.8 & 0.7 & 3.2 & 12 & 14 & 7.8 & 7.1 \\
\hline \multicolumn{8}{|c|}{ Thermal aged } \\
\hline \multirow[t]{2}{*}{1 week } & 38 & 579 & 61 & 6.2 & 19 & 4.8 & 5.0 \\
\hline & 40 & 246 & 60 & 4.4 & 14 & 4.2 & 4.0 \\
\hline$m v$ & 39 & 413 & 61 & 5.3 & 17 & 4.5 & 4.5 \\
\hline rel md \% & 2.6 & 40 & 0.8 & 17 & 15 & 6.7 & 11 \\
\hline \multirow[t]{2}{*}{2 weeks } & 39 & 532 & 66 & 6.4 & 17 & 7.1 & 10 \\
\hline & 40 & 585 & 54 & 4.8 & 15 & 6.4 & 9.0 \\
\hline$m v$ & 40 & 559 & 60 & 5.6 & 16 & 6.8 & 9.5 \\
\hline rel md \% & 1.3 & 4.7 & 10 & 14 & 6.3 & 5.2 & 5.3 \\
\hline \multirow[t]{2}{*}{4 weeks } & 67 & 532 & 104 & 6.6 & 18 & 12 & 12 \\
\hline & 35 & 497 & 65 & 7.0 & 18 & 8.2 & 8.0 \\
\hline$m v$ & 51 & 515 & 85 & 6.8 & 18 & 10 & 10 \\
\hline rel md \% & 31 & 3.4 & 23 & 3.1 & 0.0 & 19 & 20 \\
\hline \multicolumn{8}{|c|}{ Moisture aged } \\
\hline \multirow[t]{2}{*}{1 week } & 34 & 603 & 67 & 7.7 & 20 & 25 & 27 \\
\hline & 32 & 632 & 96 & 9.3 & 21 & 11 & 12 \\
\hline$m v$ & 33 & 618 & 82 & 8.5 & 21 & 18 & 20 \\
\hline rel md \% & 3.0 & 2.3 & 18 & 9.4 & 2.4 & 38 & 38 \\
\hline \multirow[t]{2}{*}{2 weeks } & 38 & 746 & 44 & 4.4 & 17 & 32 & 42 \\
\hline & 40 & 734 & 41 & 3.0 & 17 & 25 & 30 \\
\hline$m v$ & 39 & 740 & 43 & 3.7 & 17 & 28 & 36 \\
\hline rel md \% & 2.6 & 0.8 & 3.5 & 19 & 0.0 & 12 & 17 \\
\hline \multirow[t]{2}{*}{4 weeks } & 37 & 677 & 60 & 8.1 & 20 & 11 & 12 \\
\hline & 30 & 624 & 58 & 5.9 & 18 & 21 & 22 \\
\hline$m v$ & 34 & 651 & 59 & 7.0 & 19 & 16 & 17 \\
\hline rel md \% & 10 & 4.1 & 1.7 & 16 & 5.3 & 29 & 29 \\
\hline
\end{tabular}

$\mathrm{t}_{\text {ign }}$-time to ignition

$\mathrm{t}_{\text {ext }}$-time to extinguishment

$m v$ is the mean value of the duplicate tests and rel $m$ d $\%$ is the relative mean deviation in percentage from the mean value

3.3.2.1. Samples Aged by Thermal Exposure Samples aged for 1 and 2 weeks generally showed good and acceptable repeatability with regards to time to ignition. The 4-weeks aged samples differed considerably in time to ignition. One of the two samples had twice as long ignition time. Regarding the peak HRR, the sample with longest time to ignition showed almost twice as high peak HRR while the THR was identical. Also, TSP was significantly higher for the sample with the longer time to ignition and higher peak HRR.

Comparing the aged samples with the unaged, the time to ignition was similar and not significantly affected by the thermal ageing, except for one of the samples aged for 4 weeks, which seems to be deviating. The peak HRR, shown in Fig. 5 in 


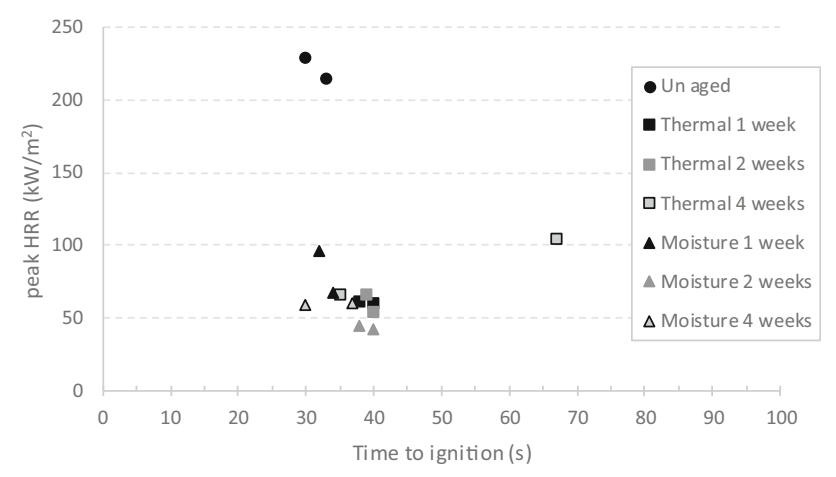

\section{Figure 5. Peak heat release rate versus time to ignition for the cone calorimeter tests with FRP 3.}

relation to time to ignition, is however significantly lower for the aged samples compared with the unaged samples, as well as the THR and smoke production (see Table 2). The THR for all the aged samples were much lower compared with the unaged and does not seem to change as the ageing time increase.

Also, the smoke productionFigure 5 was much lower for the aged samples. The unaged samples showed one large initial peak followed by a second peak. All thermally aged samples showed an initial peak, at the same time as the unaged, but not as high. The aged samples did not show a second peak as clearly as the unaged sample. Hence, the smoke production decreased for the aged samples. It can be seen from the TSP values in Table 2, that samples aged for 1 week showed the lowest smoke production. The 2- and 4-weeks aged samples showed an increase compared to 1-week aged samples but still very low compared to the unaged.

3.3.2.2. Samples Aged by Moisture Exposure All moisture aged samples showed good repeatability for the duplicate tests regarding the ignition time. Samples aged for 1 week showed variation in the peak HRR and a larger variation in smoke production. However, the THR was almost identical. The 2-weeks aged samples showed good repeatability for all parameters. The 4-weeks aged samples also showed good repeatability with exception for the smoke production, where there was a quite large variation. The deviation between the duplicate samples is considered as not good as it is higher than $10 \%$ from the mean value. However, the smoke production was low, and the results were thus considered to be acceptable.

When comparing the moisture aged samples with the unaged, the time to ignition was just slightly affected. As was the case for the thermally aged samples, all samples showed a very significant decrease in peak HRR, as shown in Fig. 5. The values were less than half of the values for the unaged samples, and of similar magnitude as those for the thermally aged samples. The THR for the moisture aged samples were lower than that for the unaged samples in all cases. From the TSP-values in Table 2, it can be seen that the results were more scattered. The 
samples aged for 1 and 4 weeks showed as an average a decrease, but samples aged for 2 weeks performed very similar to the unaged.

\subsection{Smoke Chamber with FTIR Gas Analysis}

The results from the smoke chamber tests with FTIR gas analysis of the three composite laminates, FRP 1, FRP 2 and FRP 3, are presented below. The results of the smoke obscuration measurements are presented in Table 3 . The results on the toxic gas content with maximum concentrations are presented as bar graphs in Fig. 6, Fig. 7, Fig. 8 and Fig. 9. These bar graphs are showing the mean value of the duplicate tests with error bars showing the spread of individual results.

3.4.1. FRP 1 Laminate There was no ignition in any of the tests with FRP 1. There was thus smoke production from pyrolysis only, resulting in a moderate but gradually increased specific optical density $\left(\mathrm{D}_{\mathrm{s}}\right)$ with time. Detected gas species were $\mathrm{CO}_{2}, \mathrm{CO}, \mathrm{HCN}$ and $\mathrm{HCl}$. Figure 10 shows the gas species content as it changes with time for the unaged sample in test 1 . There was a continuous increase in $\mathrm{CO}_{2}, \mathrm{CO}$ and $\mathrm{HCN}$. Regarding $\mathrm{HCl}$, there was an initial peak in the first part of the test followed by a decrease. Late in test, there was again an increase in the $\mathrm{HCl}$ content. All samples, unaged, thermal aged and moisture aged, showed the same general behaviour in the growth pattern of gas specie content.

3.4.1.1. Samples Aged by Thermal Exposure The maximum specific optical density $\left(\mathrm{D}_{\mathrm{s}, \max }\right)$ measured increased somewhat for the aged laminate samples with increasing ageing time. There was an increase in $\mathrm{CO}_{2}$ for the 1-week aged sample and a decrease for the 2- and 4-weeks aged samples. All aged samples had an increase in $\mathrm{CO}$ but a decrease in $\mathrm{HCN}$ compared to the unaged. Regarding $\mathrm{HCl}$, the 1-week aged samples had a higher maximum content than the unaged, but there was a decrease of $\mathrm{HCl}$ for the 2- and 4-weeks aged samples. One should note that the repeatability between the duplicate test were generally lower for $\mathrm{HCl}$ compared to the other gas compounds measured.

\subsubsection{Samples Aged by Moisture Exposure Regarding smoke production, the} samples aged for one and two weeks showed an increase in $\mathrm{D}_{\mathrm{s}}$, max. But there was no significant difference between the unaged samples and the four weeks aged samples. The gas measurement showed a limited impact on $\mathrm{CO}_{2}$ for the 1-week aged samples and a decrease for the 2-weeks aged samples. The 4-weeks aged samples showed an increase compared to the unaged samples. All aged samples had an increase in $\mathrm{CO}$ compared to the unaged samples and a decrease in $\mathrm{HCN}$ and $\mathrm{HCl}$.

3.4.2. FRP 2 Laminate None of the samples of the FRP 2 laminate ignited in the smoke chamber and there was only smoke production from pyrolysis, resulting in a low $\mathrm{D}_{\mathrm{s} \text {, max }}$. The repeatability of the duplicate samples, unaged, thermal aged as well as moisture aged, was within the tolerance of the test method. The detected species were $\mathrm{CO}_{2}, \mathrm{CO}, \mathrm{HCN}$ and $\mathrm{HCl}$. The growth of the gas specie content with 
Table 3

Smoke Chamber Results

\begin{tabular}{|c|c|c|c|c|c|c|c|c|c|}
\hline \multirow[b]{2}{*}{$\begin{array}{l}\text { Ageing } \\
\text { time }\end{array}$} & \multicolumn{3}{|c|}{ FRP 1} & \multicolumn{3}{|c|}{ FRP 2} & \multicolumn{3}{|c|}{ FRP 3} \\
\hline & $\begin{array}{l}\mathrm{t}_{\mathrm{ign}} / \\
\mathrm{t}_{\mathrm{ext}}(\mathrm{s})\end{array}$ & $\mathrm{D}_{\mathrm{s}, \max }$ & $\begin{array}{c}\text { Time to } \\
\mathrm{D}_{\mathrm{s}, \max }(\mathrm{s})\end{array}$ & $\begin{array}{c}\mathrm{t}_{\mathrm{ign}} / \\
\mathrm{t}_{\mathrm{ext}}(\mathrm{s})\end{array}$ & $\mathrm{D}_{\mathrm{s}, \max }$ & $\begin{array}{c}\text { Time to } \\
D_{\mathrm{s}, \max }(\mathrm{s})\end{array}$ & $\begin{array}{c}t_{\text {ign }} / \\
t_{\text {ext }}(s)\end{array}$ & $\mathrm{D}_{\mathrm{s}, \max }$ & $\begin{array}{c}\text { Time to } \\
\mathrm{D}_{\mathrm{s}, \max }(\mathrm{s})\end{array}$ \\
\hline \multirow[t]{2}{*}{ Unaged } & $\mathrm{NI} /-$ & 151 & 362 & $\mathrm{NI} /-$ & 105 & 458 & $\mathrm{NI} /-$ & 81 & 291 \\
\hline & NI/- & 128 & 352 & $\mathrm{NI} /-$ & 100 & 396 & $36 ; 61 /$ & & \\
\hline $47 ; 262$ & 19 & 39 & & & & & & & \\
\hline$m v$ & & 140 & 357 & & 103 & 427 & & 50 & 165 \\
\hline $\begin{array}{c}\text { rel md } \\
\%\end{array}$ & & 8.2 & 1.4 & & 2.4 & 7.3 & & 62 & 79 \\
\hline \multicolumn{10}{|c|}{ Thermal aged } \\
\hline \multirow[t]{2}{*}{1 week } & $\mathrm{NI} /-$ & 155 & 420 & $\mathrm{NI} /-$ & 99 & 431 & $\mathrm{NI} /-$ & 57 & 267 \\
\hline & $\mathrm{NI} /-$ & 159 & 340 & $\mathrm{NI} /-$ & 95 & 410 & $\mathrm{NI} /-$ & 39 & 342 \\
\hline$m v$ & & 157 & 380 & & 97 & 421 & & 48 & 305 \\
\hline $\begin{array}{c}\text { rel md } \\
\%\end{array}$ & & 1.3 & 11 & & 2.1 & 2.5 & & 19 & 12 \\
\hline \multirow[t]{2}{*}{2 weeks } & NI/- & 158 & 355 & $\mathrm{NI} /-$ & 98 & 399 & NI/- & 59 & 310 \\
\hline & $\mathrm{NI} /-$ & 167 & 440 & $\mathrm{NI} /-$ & 100 & 385 & $\mathrm{NI} /-$ & 44 & 285 \\
\hline$m v$ & & 163 & 398 & & 99 & 392 & & 52 & 298 \\
\hline $\begin{array}{c}\text { rel md } \\
\%\end{array}$ & & 2.8 & 11 & & 1.0 & 1.8 & & 15 & 4.2 \\
\hline \multirow[t]{2}{*}{4 weeks } & $\mathrm{NI} /-$ & 174 & 375 & $\mathrm{NI} /-$ & 104 & 388 & $90 / 263$ & 21 & 201 \\
\hline & $\mathrm{NI} /-$ & 165 & 363 & $\mathrm{NI} /-$ & 99 & 409 & $\mathrm{NI} /-$ & 59 & 280 \\
\hline$m v$ & & 170 & 369 & & 102 & 399 & & 40 & 241 \\
\hline $\begin{array}{c}\text { rel md } \\
\%\end{array}$ & & 2.7 & 1.6 & & 2.5 & 2.6 & & 48 & 16 \\
\hline \multicolumn{10}{|c|}{ Moisture aged } \\
\hline \multirow[t]{2}{*}{1 week } & $\mathrm{NI} /-$ & 171 & 362 & $\mathrm{NI} /-$ & 90 & 405 & $\mathrm{NI} /-$ & 47 & 293 \\
\hline & $\mathrm{NI} /-$ & 160 & 360 & $\mathrm{NI} /-$ & 95 & 448 & $\mathrm{NI} /-$ & 54 & 318 \\
\hline$m v$ & & 166 & 361 & & 93 & 427 & & 51 & 306 \\
\hline $\begin{array}{c}\text { rel md } \\
\%\end{array}$ & & 3.3 & 0.3 & & 2.7 & 5.0 & & 6.9 & 4.1 \\
\hline \multirow[t]{2}{*}{2 weeks } & NI/- & 171 & 397 & NI/- & 86 & 431 & $\mathrm{NI} /-$ & 55 & 335 \\
\hline & $\mathrm{NI} /-$ & 183 & 370 & $\mathrm{NI} /-$ & 91 & 431 & $\mathrm{NI} /-$ & 52 & 351 \\
\hline$m v$ & & 177 & 384 & & 89 & 431 & & 54 & 343 \\
\hline $\begin{array}{c}\text { rel md } \\
\%\end{array}$ & & 3.4 & 3.5 & & 3.8 & 0.0 & & 2.8 & 2.3 \\
\hline \multirow[t]{2}{*}{4 weeks } & $\mathrm{NI} /-$ & 148 & 390 & $\mathrm{NI} /-$ & 92 & 460 & $82 / 263$ & 18 & 147 \\
\hline & $\mathrm{NI} /-$ & 144 & 455 & $\mathrm{NI} /-$ & 83 & 481 & $\mathrm{NI} /-$ & 47 & 319 \\
\hline$m v$ & & 146 & 423 & & 88 & 471 & & 33 & 233 \\
\hline $\begin{array}{c}\text { rel md } \\
\%\end{array}$ & & 1.4 & 7.7 & & 5.1 & 2.2 & & 45 & 37 \\
\hline
\end{tabular}

$\mathrm{t}_{\text {ign }}$-time to ignition

$\mathrm{t}_{\mathrm{ext}}$-time to extinguishment

$m v$ is the mean value of the duplicate tests and rel $m d \%$ is the relative mean deviation in percentage from the mean value 


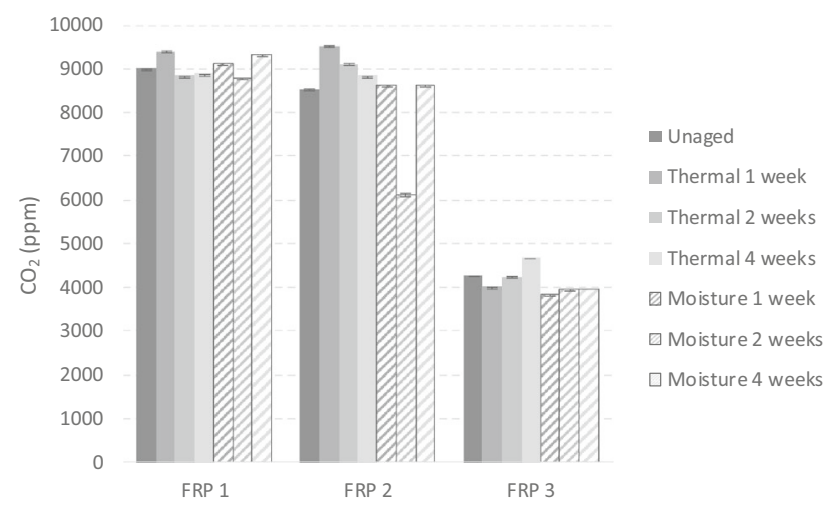

Figure 6. Maximum content of $\mathrm{CO}_{2}(\mathrm{ppm})$ in the smoke from the composite laminates during smoke chamber tests. Graph showing average values from duplicate samples with error bars of mean deviation.

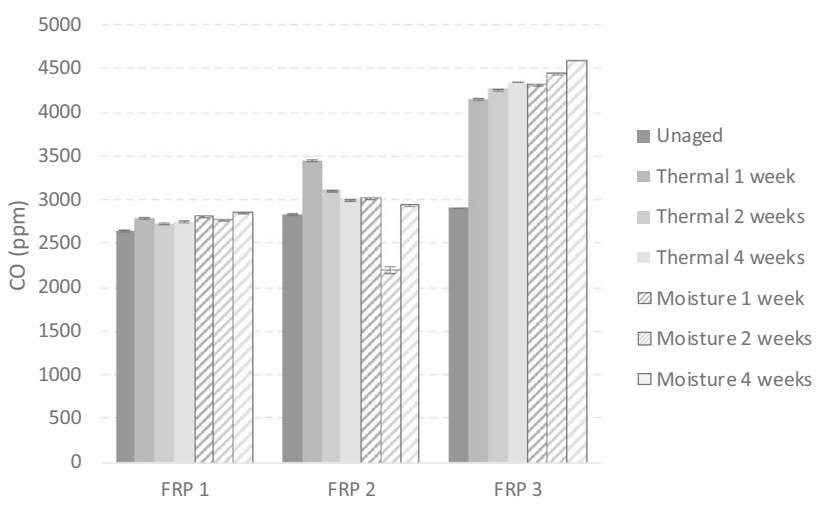

Figure 7. Maximum content of $\mathrm{CO}(\mathrm{ppm})$ in the smoke from the composite Iaminates during smoke chamber tests. Graph showing average values from duplicate samples with error bars of mean deviation.

time showed the same general behaviour as for the FRP 1 laminate, as shown in Fig. 10. There was a continuous increase of $\mathrm{CO}_{2}, \mathrm{CO}$ and $\mathrm{HCN}$. The $\mathrm{HCl}$ had an initial peak, followed by a decrease and an increase later in the tests.

3.4.2.1. Samples Aged by Thermal Exposure There was no significant change in $\mathrm{D}_{\mathrm{s}, \max }$ after thermal exposure compared to the unaged samples. The level of smoke was very similar. All aged samples had a higher $\mathrm{CO}_{2}$ and $\mathrm{CO}$ content than the unaged, with the highest content for the 1-week aged samples. There was further a decreasing trend in $\mathrm{HCN}$ for the aged samples with ageing time, compared to the unaged. Samples aged for 1 and 4 weeks showed as an average a higher $\mathrm{HCl}$ concentration compared with the unaged samples. The 2-weeks aged samples 


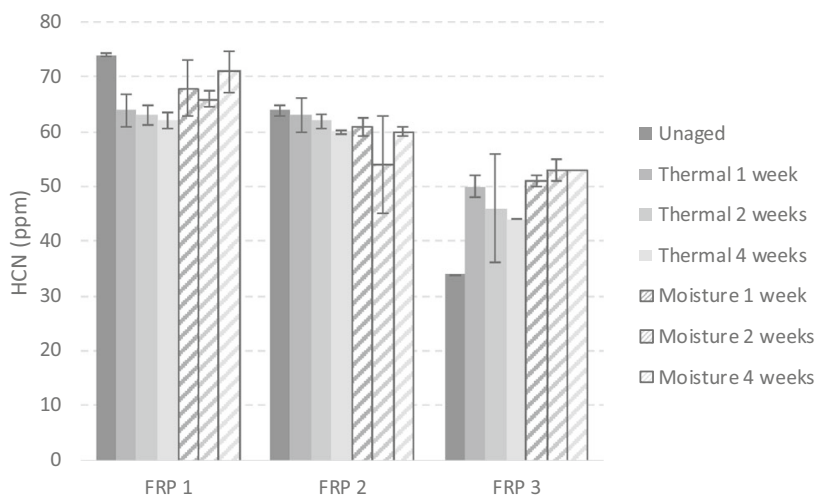

Figure 8. Maximum content of HCN (ppm) in the smoke from the composite laminates during smoke chamber tests. Graph showing average values from duplicate samples with error bars of mean deviation.

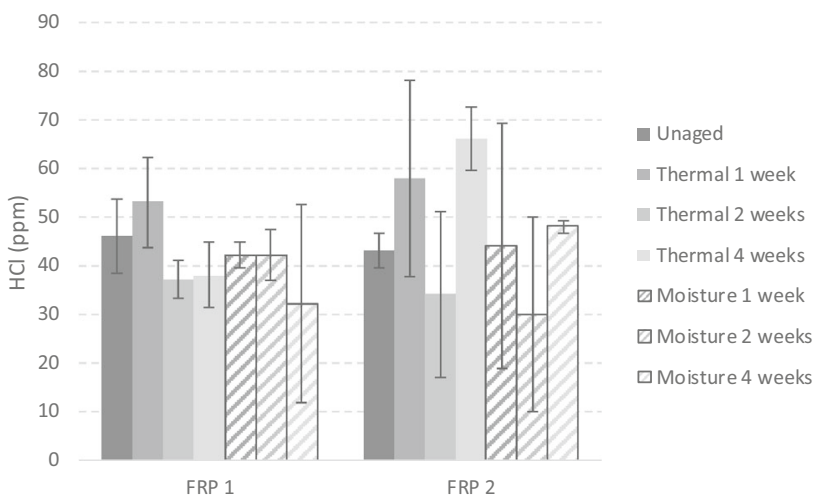

Figure 9. Maximum content of $\mathrm{HCl}(\mathrm{ppm})$ in the smoke from the composite laminates during smoke chamber tests. Graph showing average values from duplicate samples with error bars of mean deviation.

showed as an average a lower value of $\mathrm{HCl}$. However, the repeatability for $\mathrm{HCl}$ was very poor for the 1- and 2-weeks samples.

3.4.2.2. Samples Aged by Moisture Exposure There was a small decrease in $\mathrm{D}_{\mathrm{s}, \max }$ for all aged samples compared to the unaged samples. There was no significant change in $\mathrm{CO}_{2}$ for the 1- and 4-weeks aged samples compared to the unaged samples, however, the 2-weeks aged samples showed a significant decrease in $\mathrm{CO}_{2}$. There was a slight increase in $\mathrm{CO}$ for the 1- and 4-weeks aged samples and, again, the 2-weeks aged samples showed a significant lower concentration. 


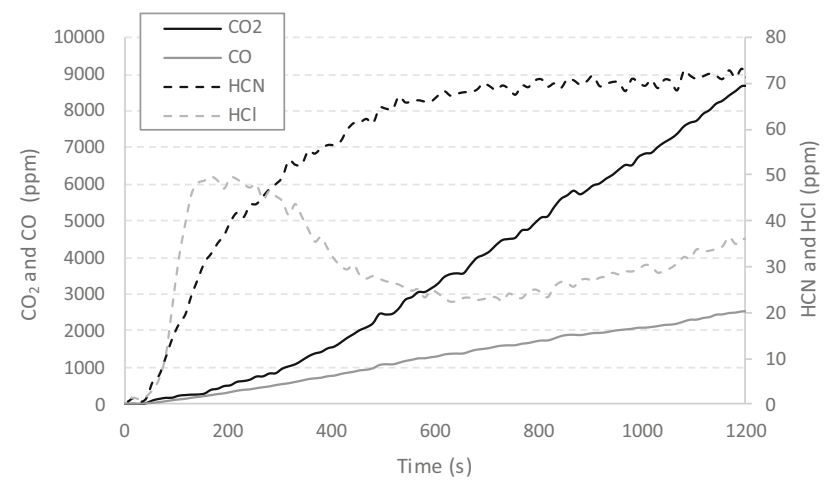

\section{Figure 10. Gas specie content with time in the smoke chamber test of the unaged FRP 1 laminate (test 1 ).}

All aged samples gave a lower $\mathrm{HCN}$ content. There was no significant change in $\mathrm{HCl}$ for the 1- and 4-weeks aged samples compared to the unaged. The 2-weeks aged samples had as an average, significant lower $\mathrm{HCl}$. But again, one should note the poor repeatability for $\mathrm{HCl}$.

3.4.3. FRP 3 Laminate The FRP 3 laminate showed generally no ignition in the smoke chamber, except for three of the samples. One of the unaged samples (test 2) ignited at $36 \mathrm{~s}$, extinguished at $47 \mathrm{~s}$, re-ignited at $61 \mathrm{~s}$ and then extinguished at $262 \mathrm{~s}$. One of the thermal exposed samples aged for 4 weeks (test 1) ignited at $90 \mathrm{~s}$ and extinguished at $263 \mathrm{~s}$. The 4 weeks moisture aged sample (test 1) ignited at $82 \mathrm{~s}$ and extinguished at $263 \mathrm{~s}$. As a result, the repeatability of the duplicates of the unaged and the 4-weeks aged samples was low. In fact, the gas production should not be compared between these tests. When a sample ignites in the smoke chamber test, products from flaming combustion emits (i.e. predominantly $\mathrm{CO}_{2}$ ) and the smoke production is normally reduced. As stated by ISO 5659-2 and IMO FTP Code 2010 Part 2, different burning behaviour due to ignition and no ignition of the samples is not considered as reason for re-testing. However, the effect of accelerated ageing on the FRP 3 laminate has to be discussed separately for samples without ignition and samples with ignition.

Detected gas species were in all cases $\mathrm{CO}_{2}, \mathrm{CO}$ and $\mathrm{HCN}$. In Fig. 11, the gas specie content with increasing time shows the different behaviour between the unaged sample without ignition (test 1) and with ignition (test 2). All detected gas species showed an increase in content with increasing time and the maximal concentration was detected in the end of the tests. The figure clearly shows the effect from flaming or non-flaming combustion conditions in the tests. When flaming combustion occurs, the production of $\mathrm{CO}_{2}$ was higher, and $\mathrm{CO}$ lower compared to tests with no ignition. The results of the gas specie content from samples with no ignition is shown in Fig. 6, Fig. 7, Fig. 8 and Fig. 9. Results from samples with ignition is shown in Fig. 12 and Fig. 13. 


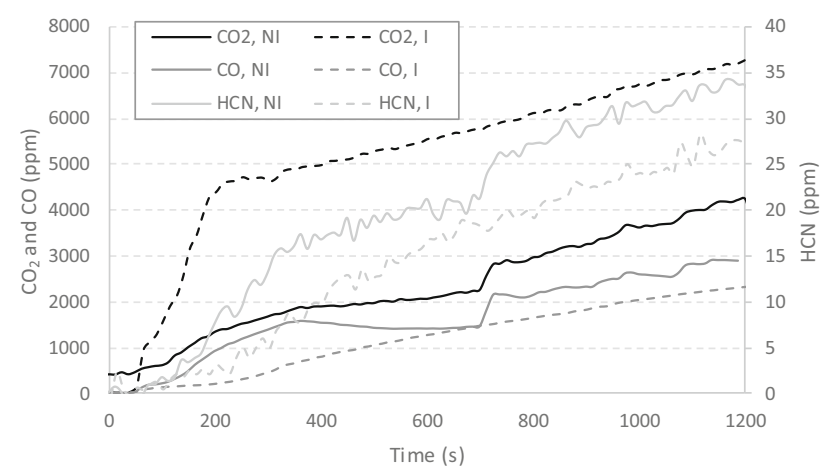

Figure 11. Gas specie content with time in the smoke chamber tests of the unaged FRP 3 laminate, test 1 with no ignition (NI) and test 2 with ignition (I).

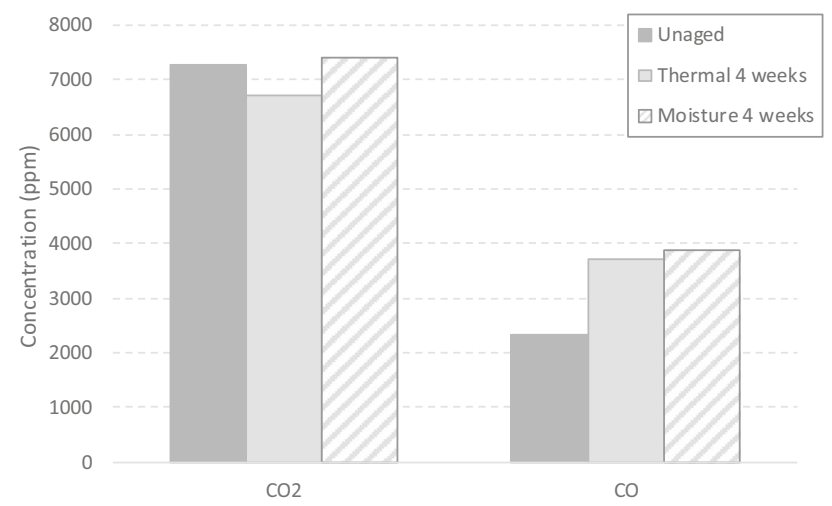

\section{Figure 12. Maximum content of $\mathrm{CO}_{2}$ and $\mathrm{CO}$ for FRP 3 samples with flaming combustion.}

3.4.3.1. Samples aged by Thermal Exposure Generally, the thermally aged samples showed a lower smoke production $\left(\mathrm{D}_{\mathrm{s}, \max }\right)$ compared with the unaged sample that did not ignite (see Table 3). The unaged sample with ignition and the 4-weeks aged sample which did ignite, both showed similar significantly lower $D_{s, \max }$ values. It would be expected that ignition and flaming combustion would result in a lower smoke production.

Comparing the results of the samples with no ignition, shows that there was a decrease in $\mathrm{CO}_{2}$ for the 1-week aged samples, no significant change of the 2-week aged samples and an increase of the 4-weeks aged samples. There was a very significant increase in both the $\mathrm{CO}$ and the $\mathrm{HCN}$ content. When comparing the 4week sample with ignition, there was a decrease in $\mathrm{CO}_{2}$ and an increase in $\mathrm{CO}$ and $\mathrm{HCN}$, compared with the unaged sample that did ignite. 


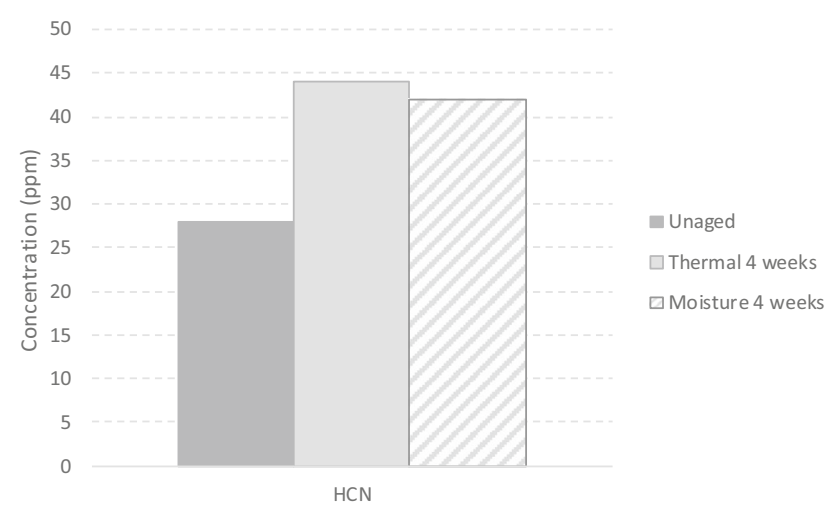

\section{Figure 13. Maximum content of HCN for FRP 3 samples with flaming combustion.}

3.4.3.2. Samples Aged by Moisture Exposure A comparison between the samples with no ignition, show that there was a decrease in $D_{s}$, max for the aged samples in relation to the unaged samples. Comparing the samples with ignition, unaged (test 2) and 4-weeks aged (test 1), shows that there was no change in $D_{s, \max }$.

The $\mathrm{CO}_{2}$ content decreased for the aged samples compared to the unaged sample with no ignition (test 1). Regarding the $\mathrm{CO}$ and $\mathrm{HCN}$, there was a significant increase in both cases. Comparing the samples with ignition, the unaged and the 4 weeks aged sample, show that there was no significant change in $\mathrm{CO}_{2}$. However, there was a significant increase in $\mathrm{CO}$ and $\mathrm{HCN}$ for the 4 weeks aged sample.

\section{Summary and Discussion}

The selected materials for the study are intended to be used as bulkheads and as cabin walls for ships. Before installation on board, these materials must fulfil the requirements for a Fire Restricting Material (FRM) according to the IMO FTP Code 2010, i.e. the room corner test described in Part 10 of the standard. The material is mounted at the walls and in the ceiling of the test room and a burner is located in the corner. The material is exposed to a fire exposure of $100 \mathrm{~kW}$ from the burner for $10 \mathrm{~min}$. Then the effect from the burner is increased to $300 \mathrm{~kW}$ for the next $10 \mathrm{~min}$. Parameters such as heat release rate, smoke production, flame spread, burning droplets and flashover are measured. However, the Part 10 room corner test is a large-scale fire test and is not suitable for a screening study.

Models to predict the burning behaviour in the large-scale room fire test has been developed using the test results from small scale testing with the cone calorimeter [42-45]. Test parameters such as heat release rate and smoke production are evaluated and there is thus a correlation between the cone calorimeter and the room corner test regarding the parameters measured. Moreover, both methods use the oxygen consumption method for calculating the heat release. The 


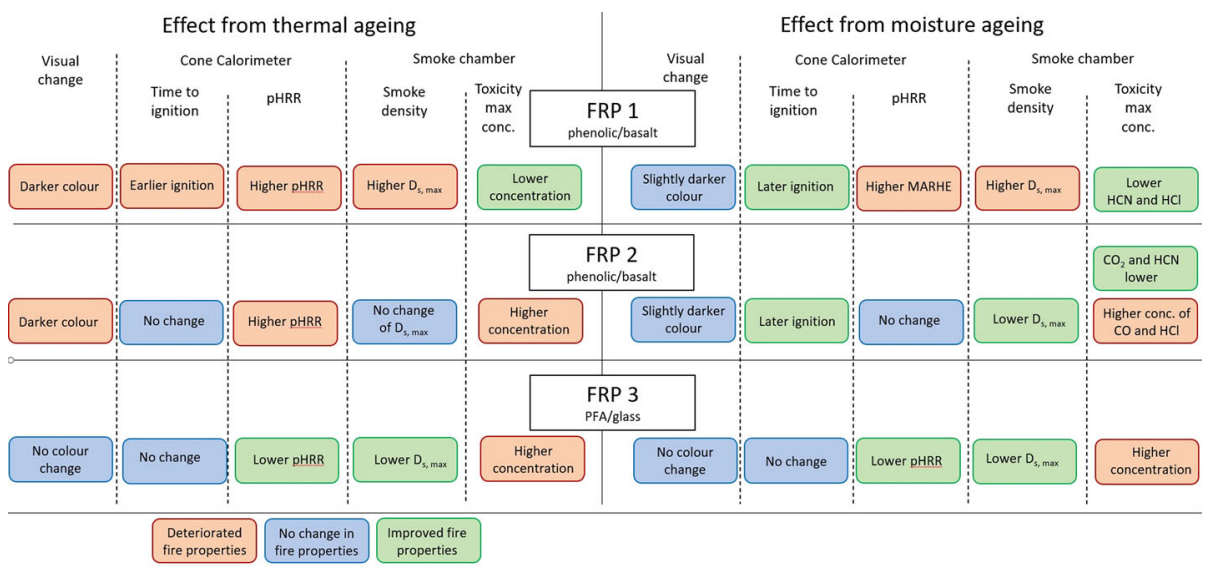

\section{Figure 14. Schematic summary of the effect from accelerated ageing with thermal exposure and moisture exposure.}

cone calorimeter was selected for the study of the accelerated ageing effect on the fire properties since this is a commonly used fire test method and easy to conduct with a large test series, as well as the correlation with the large-scale fire test. However, the correlation models are developed using the standard specimen holder described in ISO 5660-1. In the ageing study, the modified specimen holder was used. The models have not been validated with the modified specimen holder and the results can thus not be used directly as a basis for predicting fire performance in the large-scale room fire test. However, the main intention with the ageing study is to evaluate the effect of ageing on the fire performance, not to predict the large-scale fire performance.

The starting point in the study was to set up a test matrix with the ageing methods, fire test methods and time for ageing (collection of samples from ageing chambers). The number of available test samples were limited, and a decision was made to limit the number of repetitions to duplicate tests in order to increase the number of exposure times. The repeatability of these tests was in some cases relatively poor. To conduct a third test would have been valuable but was not feasible within the frames of the study. Despite the in some cases poor repeatability, there are some clear conclusions that can be made from the results. The results from the cone calorimeter tests with the thermal aged FRP 2 laminate showed deteriorated fire behaviour with an increase in heat release rate, total heat release and smoke production. The effect from the moisture exposure on the FRP 2 laminate was seen first after 4 weeks' time of exposure. After up to 2 weeks of exposure, the fire performance was similar to the unaged samples. The 4 weeks moisture aged samples showed a clear deviation in fire behaviour, as can be seen in Fig. 4. The time to ignition was much later in the test, the peak HRR was slightly lower, and the smoke production decreased. The moisture exposure seems to have caused a change in the material, which results in an improved fire performance behaviour given by the longer time to ignition. 
Similarly, as for the FRP 2 laminate, the reaction-to-fire behaviour of the thermally aged FRP 1 laminate was deteriorated with increasing heat release and smoke production with increasing ageing time. The effect from moisture ageing was limited regarding the heat release; however, the smoke production was increased, shown both in the cone calorimeter test and the smoke chamber test. The clear change in ignition time in the cone calorimeter for the 4-week moisture aged samples seen for the FRP 2 laminate was not seen for the FRP 1 laminate.

The cone calorimeter test results for the thermal aged FRP 3 laminate showed that the fire behaviour actually was improved for the aged samples. There was a slightly longer time to ignition compared to the unaged samples, and a significant decrease in heat release rate, total heat release and smoke production. The moisture aged FRP 3 samples also showed an improved fire behaviour after ageing similarly to the thermal aged, with a decrease in peak heat release rate and total heat release. Noticeable for the cone calorimeter results is the large difference between the unaged samples and the aged samples, which is clearly seen in Fig. 5. The resin in the FRP 3 laminate was PFA, which is known to have very good fire performance [38]. One possible explanation to the large difference seen could possibly be related to the manufacturing of the laminate and the curing of the resin. If the curing process of the samples were not completed, the reaction-to-fire properties could have been affected by the ageing. When the samples were exposed to thermal ageing and moisture ageing, the curing of the resin could have been more completed. However, we have no information on that the curing process has not been conducted according to normal procedure.

Tests were further conducted with the smoke density chamber according to IMO FTP Code 2010 Part 2. Materials used as surface linings and bulkheads on board ships have to fulfil certain test requirements. Regarding smoke density, $\mathrm{D}_{\mathrm{s}}$, $\max$ should be lower or equal to a value of 200 . The tests in this study were conducted with one of the three different tests modes from IMO: a heat flux of $50 \mathrm{~kW} / \mathrm{m}^{2}$ and without a pilot flame. The other two test modes from IMO includes a heat flux of $25 \mathrm{~kW} / \mathrm{m}^{2}$, in one case with and in the other without a pilot flame. None of the FRP 1 or FRP 2 samples ignited, thus only pyrolysis from the materials occurred. In the tests with the thermal aged FRP 1 samples, $\mathrm{D}_{\mathrm{s}, \max }$ increased with increasing ageing time compared to the unaged samples. The moisture aged samples also showed an increase in $\mathrm{D}_{\mathrm{s} \text {, max }}$, but only for the samples aged 1 and 2 weeks. The FRP 2 composite laminate showed similar values of $D_{s, \text { max }}$ for thermal aged samples as for the unaged samples, but there was a decrease in $\mathrm{D}_{\mathrm{s}, \max }$ for the moisture aged samples.

There was generally no ignition of the FRP 3 samples. However, one of the unaged samples ignited as well as one of the 4 weeks thermal aged samples and one 4 weeks moisture aged sample. The results in the smoke chamber test is strongly related to the combustion condition, i.e. if flaming combustion occur or not. With flaming combustion, the smoke production is lower which was seen in the tests where the FRP 3 samples ignited. The smoke density test standards, ISO 5659-2 and IMO FTP Code 2010 Part 2, states that this behaviour is not a cause for re-testing and that a mean value of the results should be reported. However, for this study, where the focus is on evaluation of the effect of accelerated ageing, 
a mean value of samples with ignition and without ignition will give misleading information. The test data was thus analysed separately for samples without ignition and with ignition. Both the thermal aged samples and the moisture aged samples without ignition had a lower $\mathrm{D}_{\mathrm{s}, \max }$ value than the unaged sample. The aged samples with ignition had no significant change in $\mathrm{D}_{\mathrm{s} \text {, max }}$ compared to the unaged sample that ignited, but they were in all cases much lower compared to the samples that did not ignite.

The requirement according to IMO FTP Code 2010 Part 2 regarding the toxicity is a content of $\mathrm{CO}$ not exceeding $1450 \mathrm{ppm}, \mathrm{HCN} 140 \mathrm{ppm}$ and $\mathrm{HCl} 600 \mathrm{ppm}$ at the time for $\mathrm{D}_{\mathrm{s}, \max }$. According to the standard, three tests should be conducted with the smoke chamber. Test 1 should be without the FTIR analysis to find the time for $D_{s, \max }$. This time is then used in the two following tests to measure the content of the toxic gases, which is only measured for $1 \mathrm{~min}$. Since the time for $\mathrm{D}_{\mathrm{s}, \max }$ often differs somewhat between samples, the time for measuring toxicity of test 2 and 3 will likely not be at the time for maximum smoke density in the specific tests. To collect data for the complete test, sampling of the smoke was instead conducted continuously, as stated in EN 17,084. However, still using the sampling probe described in the IMO Part 2 standard. Another deviation that was made from the IMO Part 2 standard was that the gas specie content reported here is the maximum concentration during the test, not necessary at the $\mathrm{D}_{\mathrm{s} \text {, max }}$. In most cases, the maximum concentration coincides with the maximum smoke density, often late in the test as the smoke accumulates. However, this is not the case for $\mathrm{HCl}$, which was shown to have the maximum concentration early in the tests.

The results showed that none of the tested samples, unaged, thermally aged or moisture aged had levels of toxic gas specie content higher than the requirement. However, the objective of the study was to investigate if ageing effected the production of toxic gases.

For FRP 1 and FRP 2, the two phenol/basalt composites, there was no ignition and thus no flaming combustion in any of the tests. It is quite common in smoke chamber tests that there is no ignition, or in cases of ignition, that the flaming combustion only continues for a short time [46]. In such cases combustion products from flaming combustion are mixed with pyrolysis products. In the tests with FRP 1 and FRP 2 only products from pyrolysis were produced and that could be seen by the high $\mathrm{CO} / \mathrm{CO}_{2}$ ratio of the gas mixture in the test chamber. There were some trends in the gas composition that could be seen for the aged samples, but they were not very significant. But typically, the concentration of $\mathrm{CO}$ was somewhat higher compared with the unaged samples and the concentration of HCN was lower. These two composites additionally produced $\mathrm{HCl}$. The concentrations measured did not give any clear picture of whether the ageing had an impact on the $\mathrm{HCl}$ production, partly due to a very poor repeatability between the duplicate samples. One thing that could have affected the measured $\mathrm{HCl}$ concentration is losses in the particle filter used for the FTIR. Although it was heated to $180^{\circ} \mathrm{C}$, it is known that there are losses in the filter, and the extent of the losses could vary between different tests. Actually, analysis of $\mathrm{HCl}$ in the particle filter is now mandatory in the IMO test method, but this was not included in this study. Over- 
all, one can say that the production of toxic gases from pyrolysis was affected from ageing for the phenol/basalt composites, but to a limited degree.

In the case of FRP 3, the PFA/glass composite, there was in fact a significant influence on the toxic gas production from ageing. Also, for this composite, there was no ignition in the majority of the tests. In these tests there was a significantly higher production of both $\mathrm{CO}$ and $\mathrm{HCN}$ in all cases, both for the thermal aged and the moisture aged samples. For $\mathrm{CO}$, a trend could be seen of increased production with increased ageing time. In case of the few tests that did gave ignition and flaming combustion, the production of $\mathrm{CO}_{2}$ was naturally much higher. The trends seen for the non-flaming tests were, however, also seen here, with clear increases in the production of both $\mathrm{CO}$ and $\mathrm{HCN}$ for the aged samples.

The present accelerated ageing study contains a lot of results and test data and the effect from ageing on the fire properties was not obvious in many cases. An overall picture of the results is presented in Fig. 14. The figure is a schematic drawing, summarizing the main results for the FRP laminates. The effect from both thermal exposure and moisture exposure on the fire properties are shown to give an easy and comparable overview. Results marked with green show an improved fire behaviour after accelerated ageing. Blue represents no significant change and red show a deteriorated fire performance after ageing. The results presented in the schematic drawings are the general result for the three exposure times of 1 week, 2 weeks and 4 weeks, meaning that even if the figure indicates an improved result, one of the exposure times could have another result. However, the figure is intended to give an overview of the effect from ageing.

As shown in Fig. 14, the fire properties of FRP 1 laminates were deteriorated after both thermal and moisture ageing. However, the toxicity was generally improved with lower concentrations after ageing. Even though FRP 1 and FRP 2 laminates both consist of phenolic resin and basalt fibres, the results are not completely the same. For the FRP 2 laminate, there is a difference in the effect from the ageing between the two exposure methods. The effect on the FRP 2 laminates showed a slightly deteriorated fire performance after thermal exposure. After moisture ageing, there was improved results in the cone calorimeter and lower Ds, max in the smoke chamber, i.e. improved fire performance. The effect on the FRP 3 laminate was the same after thermal exposure as after moisture exposure with an improved fire performance.

\section{Conclusions}

The research questions of the current study: Are the fire properties of composite materials affected by ageing? And if so, how are they affected? could be answered as it was found that ageing, both thermal exposure and moisture exposure, affects the fire behaviour. Changes occur in the material, here shown by a changed reaction-to-fire behaviour.

For FRP 1 and FRP 2, the phenol/basalt composite laminates, these changes lead to a deteriorated fire behaviour with higher heat release and a higher smoke production in the cone calorimeter tests with the thermal aged samples. The mois- 
ture ageing had less effect, only shown after 4 weeks exposure for FRP 2, with a clear increase in ignition time and a somewhat lower peak HRR. This effect thus actually resulted in better fire performance. In the smoke chamber tests with FRP 1 and FRP 2, there was no ignition and thus no flaming combustion in any of the tests. The overall low smoke production of these two composites was only slightly affected by the ageing. Regarding the production of toxic gases, typically, the production of $\mathrm{CO}$ was somewhat higher compared with the unaged samples and the production of $\mathrm{HCN}$ was instead lower. These two composites additionally produced $\mathrm{HCl}$. However, the concentrations measured did not give any clear picture of whether the ageing had an impact on the $\mathrm{HCl}$ production.

The study further showed that for FRP 3, the PFA/glass composite laminate, the fire behaviour was clearly improved, both after thermal exposure and moisture exposure, with a significant decrease in heat release and smoke production in the cone calorimeter. In the smoke chamber tests, the from the beginning already low smoke production was even lower for the aged samples compared to the unaged samples. For FRP 3, there was in fact a significant influence on the toxic gas production from ageing. There was a clearly higher production of both $\mathrm{CO}$ and $\mathrm{HCN}$ in all cases, both for the thermal aged and the moisture aged samples. For CO, a trend could be seen of increased production with increased ageing time.

This study was made with three selected composite laminates, where the two phenol/basalt laminates only differed in density. The study showed a clear impact on reaction-to-fire properties from ageing, both positive and negative. Thus, it is necessary to initiate studies in the basic properties affecting the fire safety of material. A deeper knowledge about the ageing mechanism in the materials is needed to thoroughly understand the ageing effects seen in the current work.

\section{Acknowledgements}

The research presented is a part of the RAMSSES project which has received funding under the European Union's Horizon 2020 research and innovation programme under the grant agreement No 723246 .

\section{Funding}

Open access funding provided by RISE Research Institutes of Sweden. 
Open Access This article is licensed under a Creative Commons Attribution 4.0 International License, which permits use, sharing, adaptation, distribution and reproduction in any medium or format, as long as you give appropriate credit to the original author(s) and the source, provide a link to the Creative Commons licence, and indicate if changes were made. The images or other third party material in this article are included in the article's Creative Commons licence, unless indicated otherwise in a credit line to the material. If material is not included in the article's Creative Commons licence and your intended use is not permitted by statutory regulation or exceeds the permitted use, you will need to obtain permission directly from the copyright holder. To view a copy of this licence, visit http:// creativecommons.org/licenses/by/4.0/.

\section{References}

1. ECE Regulation 118 (2019) Uniform technical prescriptions concerning the burning behaviour and/or the capability to repel fuel or lubricant of materials used in the construction of certain categories of motor vehicles, United Nations

2. EN 13501-1 (2002) Fire classification of construction products and building elements Part 1: Classification using test data from reaction to fire tests, European Standard

3. EN 45545-1 (2013) Railway applications - Fire protection on railway vehicles - Part 1: General, European standard

4. IMO-International Maritime Organization (2010) International Code for Application of Fire Test Procedures, International Maritime Organization

5. Vahabi H, Sonnier R, Ferry L (2014) Effects of ageing in the fire behaviour of flame-retardant polymers: a review. J Polym Int 64:313-328

6. Martins S, Borges L, D'Almeida JR (2011) Effects of accelerated ageing in a PTFE matrix polymer composite, Macromol Symp, pp 299/300, 92-98

7. Brown RP, Kockott D, Trubiroha P, Ketola W, Shorthouse J (1995) A review of accelerated durability tests, WAMAS Report No. 18

8. Dao B, Hodgkin JH, Krstina J, Mardel J, Tian W (2007) Accelerated ageing versus realistic ageing in aerospace composite materials. IV. Hot/Wet ageing effects in a low temperature cure epoxy composite. J Appl Polym Sci 106:4264-4276

9. Emanuelsson V, Simonson M, Gevert T (2007) The effect of accelerated ageing of building wires. Fire Mater 31:311-326

10. Fiore V, Scalici T, Calabrese L, Valenza A, La Bella G (2015) Durability of flex-basalt hybrid composites for marine applications," in International conference on composite materials, Copenhagen

11. Ghosh S, Khastgir D, Bhowmick AK, Mukunda PG (2000) Thermal degradation and ageing of segmented polyamides. Polym Degradation Stability 67:427-436

12. Le Lay F , Gutierrez J (2003) Assessment of the mechanical performance of phenolic laminates after ageing in a marine environment, In: proceedings of the ACMC/sampe conference on marine composites

13. Li J, Du BX, Liang HC, Han T, Tang QH, Qin T, Dong S (2016) Ageing Estimation of Heat-shrinkable Material Based on Analytic Hierarchy Process," In: 2016 international conference on condition monitoring and diagnosis, China 
14. Mouzakis DE, Zoga H, Galiotis C (2008) Accelerated environmental ageing study of polyester/glass fibre reinforced composites (GFRPCs). Composites Part B: Eng 39:467475

15. Nowlen SP (1991) The impact of thermal aging on the flammability of electric cables, Sandia National Laboratories, Alberquerque

16. Sinturel C, Philippart J-L, Lemaire J, Gardette J-L (1999) Photooxidation of fire retarded polypropylene I. Photoageing in accelerated conditions. Eur Polym $\mathbf{J}$ 35(10):1773-1781

17. Sinturel C, Lemaire J, Gardette J-L (1999) Photooxidation of fire retardes polypropylene II. Photooxidation mechanism. Eur Polym J 35(10):1783-1790

18. Thureson P, Nilsson M (1994) Degradation of fire properties of approved products as a result of ageing. SP Report 1994:61

19. White JR, Turnbull A (1994) Weathering of polymers: mechanisms of degradation and stabilization, testing strategies and modelling. J Mater Sci 29:584-613

20. Sandinge A, Blomqvist P, Dederichs A, Markert F (2021) The necessity of accelerated ageing in fire performance assessments of composite materials. Safety Science 141:105358

21. Atkins $\mathbf{P}$, de Paula J (2002) Atkins physical chemistry

22. Gibbs JH (1972) Sufficient conditions for arrhenius rate law. J Chem Phys 57:44734478

23. Laidler KJ (1984) The development of the arrhenius equation. J Chem Educ 61:494498

24. Sandinge A, Blomqvist P, Dederichs A 2020 Does age matter? Change of fire safety properties of composite materials, In: IOP conference series: materials science and engineering, 41st riso international symposium on material science , 942, 012042

25. ISO 5660-1 (2019) In: reaction-to-fire tests - heat release, smoke production and mass loss rate-part 1: heat release rate (cone calorimeter method) and smoke production rate (dynamic measurement), International Standard

26. "RAMSSES Project," (2020) Available: https://www.ramsses-project.eu/. [Accessed October 2020]

27. EN ISO 11358-1 (2014) Plastics-Thermogravimetry (TG) of polymers - Part 1: General principles, International Standard

28. Babrauskas V (1984) Development of the cone calorimeter - a bench-scale heat release rate apparatur based on oxygen consumption. Fire Mater 8:81-95

29. Babrauskas V (2016) The Cone Calorimeter, In: SFPE Handbook of Fire Protection Engineering, pp 952-980

30. Babrauskas V, Parker WJ (1987) Ignitability measurements with the cone calorimter. Fire Mater 11:31-43

31. ISO/TS 5660-3 (2012) Reaction-to-fire tests-Heat release, smoke production and mass loss rate-Part 3: Guidance on measurement

32. ASTM Standard E1354 (2010) Standard test method for heat and visible smoke release rates for materials and products using an oxygen consumption calorimeter

33. Sandinge A, Blomqvist P, Rahm M (2020) A modified specimen holder for cone calorimeter testing to reduce influence from specimen edges, Manuscript in writing process

34. EN ISO 5659-2 (2017), Plastics - Smoke generation-Part 2: Determination of optical density by a single-chamber test, European standard

35. EN 17084 (2019), Railway applications-Fire protection on railway vehicles-Toxicity test of materials and components, European standard 
36. Bobrowski A, Drozynski D, Grabowska B, Kaczmarska K, Kurleto-Koziol Z, Brzezinski M (2018) Studies on thermal decomposition of phenol binder using TG/DTG/DTA and FTIR-DRIFTS techniques in temperature range $20-500{ }^{\circ} \mathrm{C}$. Overseas Foundry $15: 145-151$

37. Zhang J, Mei G, Xie Z, Zhao S (2016) Curing mechanism of phenolic binder for oxidecarbon refractories. ISIJ Int 56:44-49

38. Gandini A, Belgacem MN (2014) 5 - Furans," In: Handbook of Thermoset Plastics, Plastic Design Library, pp 93-110

39. Dhand V, Mittal G, Rhee KY, Part S-J, Hui D (2015) A short review of Basalt fibre reinforced polymer composites, Composites: Part B, pp 166-180

40. Hao L, Yu W (2010) Evaluation of thermal protective performance of basalt fibre nonwoven fabrics. J Therm Anal Calorim 100(2):551-555

41. Bunsell AR, Renard J (2005) Fundamentals of Fibre Reinforced Composite Materials, Bristol. Institute of Physics Publishing, UK

42. Wickström U, Göransson U (1992) Full-scale/bench-scale correlations of wall and ceiling linings. Fire Mater 16:15-22

43. Wickström U, Göransson U (1987) Prediction of heat release rates of surface materials in large-scale fire tests based on cone calorimeter results. J Test Eval 15:364-370

44. Axelsson J, Van Hees P (2005) New data for sandwich panels on the correlation between the SBI test method and the room corner reference scenario. Fire Mater 29:53-59

45. Steen Hanssen A, Hovde PJ (2002) Prediction of time to flashover in the ISO 9705 room corner test based on cone calorimeter test results. Fire Mater 26:77-86

46. Blomqvist P, Sandinge A An experimental evaluation of fire toxicity methods, Fire Mater

Publisher's Note Springer Nature remains neutral with regard to jurisdictional claims in published maps and institutional affiliations. 